DOI 10.37882/2500-3682.2021.06.10

\title{
«ПУБЛИЧНАЯ ДИПЛОМАТИЯ» КАК ОДНА ИЗ ФОРМ КУЛЬТУРНОЙ ПОЛИТИКИ РОССИИ, ПОДДЕРЖИВАЕМАЯ ЮНЕСКО
}

\section{"PUBLIC DIPLOMACY" AS ONE OF THE FORMS OF CULTURAL POLICY IN RUSSIA SUPPORTED BY UNESCO}

\section{Guliyeva}

Summary: This article analyzes some of the ties between Russia and UNESCO in terms of the implementation of the cultural policy of "public diplomacy" in practice. The term is explained, the names of some leading Russian, Azerbaijani and European scientists are given, who consider this political strategy to be correct and useful from the point of view of enriching the population of UNESCO member countries with new cultural values. Having accumulated a number of knowledge on this issue, the author of the article comes to the conclusion that modern "public diplomacy" as one of the branches of the cultural policy of Russia within the framework of UNESCO's activities is a living and effective lever of influence on both domestic and foreign audiences with the help of a whole arsenal of different methods.

The article constantly emphasizes that "public diplomacy" is an important part of the culture of human behavior in society as a whole. Methods for enriching one or another chosen strategy and cultural values can be very different. However, they have a single core. Colliding, juxtaposing, and at times and opposing different points of view on certain forms of embodiment of this diplomacy, it is noted that culture expresses the inner world of a person, his feelings, morals and ideals.

Within the scope of the article, a discussion is developed around the issue of using the so-called "soft" or, on the contrary, "hard" power as forms of "public diplomacy". From the conclusions and generalizations made in the work, it followed that these concepts, with all their grammatical opposition in cultural studies and politics, do not contradict each other. Moreover, they organically complement each other. For the purpose of proof, the work presents the judgments on this score of prominent researchers - Starchak, on the one hand, and the opposite - Dolinsky, on the other. But surprisingly, these different approaches to the implementation of forms of public diplomacy coincide.

Keywords: UNESCO, public diplomacy, cultural code, spiritual culture, creation, humanism, "hard power", "soft power".

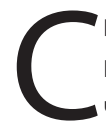
воеобразие и даже уникальность современной культуры заключается в переориентации многочисленных прежних оценок в сторону решительного утверждения новых нравственно-идейных убеждений. Видоизменение шкалы эстетических критериев в России оказывает заметное влияние и на характер проявления различных тенденций во всём цивилизованном мире.

\author{
Кулиева Ламия Аскер гызы \\ К.филол.н., дочент, Бакинский славянский университет, \\ Азербайджан \\ lama2022@inbox.ru
}

Аннотация: В представленной статье анализу подвергнуты некоторые связи России с ЮНЕСКО в аспекте реализации в практику культурной политики «публичной дипломатии». Разъяснён термин, даны фамилии некоторых ведущих русских, азербайджанских и европейских учёных, считающих данную политическую стратегию верной и полезной с точки зрения обогащения населения стран-членов ЮНЕСКО новыми культурными ценностями. Аккумулировав целый ряд знаний по настоящему вопросу, автор статьи приходит к выводу, что современная «публичная дипломатия» как одна из ветвей культурной политики России в рамках деятельности ЮНЕСКО - это живой и действенный рычаг влияния как на массовую аудиторию людей во всём мире.

В статье постоянно подчёркивается, что «публичная дипломатия» является важной частью культуры поведения человека в обществе в целом. Методы обогащения той или иной избранной стратегии и культурными ценностями могут быть самыми разными. Вместе с тем у них имеется единый стержень. Сталкивая, сопоставляя, а временами и противопоставляя различные точки зрения на те или иные формы воплощения указанной дипломатии, отмечается, что культура выражает внутренний мир человека, его чувства, нравы и идеалы.

В объёме статьи развёрнута дискуссия вокруг вопроса 06 использовании так называемой «мягкой» или, напротив, «жёсткой» силы как форм «публичной дипломатии». Из выводов и обобщений, сделанных в работе, последовало, что эти понятия при всей своей грамматической противопоставленности в культурологии и политике не противоречивы. Напротив, органично друг друга дополняют. В целях доказательства, в работе приведены суждения на этот счёт видных исследователей - Старчака, с одной стороны, и противоположное - Долинского - с другой. Но удивительным образом эти разные подходы при реализации форм публичной дипломатии совпадают.

Ключевые слова: ЮНЕСКО, публичная дипломатия, культурный код, духовная культура, творчество, гуманизм, «Жёсткая сила», «Мягкая сила».

Известный русский учёный-литературовед Н. Иванова указывает на тотальную «смену всевозможных кодов, потому что состоялись уже тотальные изменения самой культуры» [3, с.283]. С.И. Тимина поясняет, в чём же основная причина этой полной смены культурных кодов. На её взгляд, она связана с противоречиями в русской культуре «массовой - «низкой», с одной стороны, и элитарной «высокой» - с другой [11, с.7]. Критик поясняет, 
что «как раз всё дело и заключается в такой мере, потому и вряд ли надо страстно радоваться идеям конвергенции элитарной и массовой культуры» [11, с.7]. Это мнение подтверждает и культуролог с мировым именем Ю.М. Лотман. Данная проблема в русской культуре на рубеже веков, действительно, открыта к размышлениям и предоставляет рядовым людям додумывать, домысливать, делая собственные выводы. Более того, культурные коды, о функционировании которых пишут Иванова, Тимина, Лотман и другие, только подтверждают мысль об их связи с развитием мировых цивилизаций. Совершенно прав Этибар Наджафов, констатирующий: «Мировая цивилизация, как интернациональное явление, образуется прежде всего из ценностей культуры, принадлежащих различным народам» [7, с.104].

От этих и подобного рода заявлений, на наш взгляд, можно протянуть прямые нити к распространённой в последние годы в России «публичной дипломатии» - системе насущных культурных запросов, активно внедряемых в массы. О том, что это эффективная стратегическая линия в политике современной РФ, подтверждают и в ЮНЕСКО. Так, в одном из докладов на форуме под названием «Культурологический диалог цивилизаций» было озвучено, что в её странах-членах «было бы совсем неплохо показывать одаренных, независимых, пассионарных и успешных россиян» [5, с.111]. Возможно, правительство России могло бы пройти мимо такого заявления, посчитав это субъективным мнением одного из докладчиков от ЮНЕСКО. Однако существо вопроса для политиков или чиновников России гораздо глубже. Западная пресса в целях очернить культуру населения России усиленно муссирует слухи о «международной широкой аудитории, демонстрирующей на телеэкранах хмурых неулыбчивых граждан в серо-чёрных тонах с картинками унылых районов, где в моно-городах ютятся простые рабочие» [8]. Учитывая размах подобного рода информации в западных СМИ, в телекомпании России всё чаще приходят к выводу о необходимости демонстрации привлекательных ярких пейзажей, с достопримечательностями, красивым внешним антуражем городов и т.д.

Такая дипломатичная форма подачи периодически обновляющейся по разным регионам информации играет ключевую роль и всецело приветствуется в ЮНЕСКО. В чём же заключается её позитивное предназначение? Вопервых, «публичная дипломатия» - это своего рода программа окультуривания нации в лучшем смысле этого слова. Последовательно проходя ряд стадий, она приобретает ярко выраженную гуманистическую направленность. Это панацея в сущности любой стратегии, которая непременно поддерживается и в ЮНЕСКО. Прав один из ведущих культурологов Азербайджана Фуад Мамедов, утверждающий, что именно с провозглашения гуманистического пафоса культуры во все времена начинается определённая и политическая линия в государствах.

Учёный пишет: «Благодаря усилиям гуманистов постепенно не только умение, организованность и нравственность но, прежде всего научное знание и созидательная деятельность становились главной движущей силой развития культуры человека и общества» [4, с.62]. Это бесспорное положение также признаётся и в ЮНЕCKO.

Если конгломерат научных знаний, умений, созидательная деятельность, усиленных этико-нравственными аспектами, так силён (а это подчёркивает азербайджанский учёный-культуролог), то симптоматично возрастает и роль межправительственных организаций. К ним в первую очередь относится ЮНЕСКО. Следует признать, что конец второго десятилетия XXI в. ставит перед этой Организацией крупномасштабные задачи, что в условиях глобализации для ряда государств имеет важное и принципиальное значение. Россия же (разумеется, помимо всевозможных форм и методов воздействия на мировую общественность и обеспечения безопасности собственной державы) возлагает определённые перспективы на так называемую публичную дипломатию.

Вдумаемся в смысл этих слов. С одной стороны, это работа правительства, силовых структур и учёных культурологов, политиков, историков, философов по расширенному привлечению кадров самого широкого профиля. Государство и ЮНЕСКО совместными усилиями изыскивают, мобилизуют и по мере возможностей используют последние достижения в разных сферах. С другой стороны, суть первой части названия - публичность, бесспорно, ориентирует на «гласность». Итак, эта такая форма современной культурной политики, которая в период глобализации опирается на всевозможные факторы взаимообогащения культур. Например, создание условий для проведения культурного диалога. Известный русский политик и культуролог Г. Померанцев фиксирует: «Диалог - это разговор, в котором дух целого возникает и прокладывает себе дорогу сквозь различия реалий. В идеале в таком диалоге все собеседники внимательно прислушиваются к правде целого, и гегемония принадлежит тому, кто горит желанием утвердить своё сложившееся мнение по вопросам культуры и образования, а пальма первенства принадлежит тем, кто держит ворота истины открытыми» [9, с.61-62].

Несмотря на велеречивость тона и даже наличие в строго научном тексте метафоры, под настоящим определением в рамках публичной дипломатии следует понимать такого рода диалог как открытый, полемичный, толерантный, равноправный. Понятно и то, что такой диалог в дипломатии нуждается в хорошей предварительной подготовке. И на современном этапе ЮНЕСКО отведена большая роль по созданию условий для него. 
В Уставе Организации зафиксировано: «Только посредством такого диалога между культурами, цивилизациями и народами современный мир придёт к глобальному осознанию устойчивого и планомерного дальнейшего развития, которое потенциально охватит соблюдение юридических прав личности, включая факторы взаимного уважения и уменьшения в мире уровня нищеты. Всё это является сутью миротворческой миссии и центральной деятельности ЮНЕСКО» $[12$, с.7]. Добавим, что эта миссия является также важной частью «публичной дипломатии», ныне разрабатываемой в России.

Скажем больше того, периодическое проведение этого диалога объективно призвано содействовать укреплению мира между государствами-членами ЮНЕСКО, что симптоматично повысит и общий культурный уровень народов. Культурный диалог входит в стратегию Организации, одновременно формируя цели и задачи международных сообществ. Успех же обеспечивает уникальная сфера компетенций ЮНЕСКО, которая охватывает, как далее записано в Уставе, не только культуру, образование и науку (то есть генерализирующие факторы), но также информацию и коммуникацию» $[12$, с.2.]

Один из видных европейских культурологов фиксирует, что «в результате отрытого и взаимно обогащающего страны диалога, встают также и вопросы сохранения, развития и дальнейшего преумножения культурно-гуманитарного наследия государств-членов ЮНЕСКО и эффективного использования этого арсенала на внешнеполитической арене в целом» [14, с.17].

Однако ключевые функции «публичной дипломатии» только завоеванием культурных ценностей в России не ограничивается. Сфера их распространения значительно шире. Так, главы государств РФ В. Путин и Д. Медведев в своих выступлениях на различных международных форумах, саммитах и совещаниях неоднократно указывают, что главными задачами внешней политики страны и «публичной дипломатии» соответственно являются достижения, в первую очередь содействующие модернизации экономики. Волнует правительство РФ на современном этапе и вопросы поддержания стабильности в мировом масштабе. Д. Медведев подчёркивал: «При современных острых противоречиях на политической мировой арене очевидно в наши дни стремление к гармонии, установка на взаимно выгодные диалоги, снижение уровня конфликтности» [6, с.11].

По мнению многих прогрессивно мыслящих политиков и культурологов, важным элементом в «публичной дипломатии» является плодотворное сотрудничество между странами, достижения обоюдного согласия по многим культурным, экономическим и общественно-политическим вопросам. Именно дипломатию в пределах гласности (только в современном толковании слова, не имеющего практически ничего общего с той пресловутой гласностью, которая была в своё время провозглашена М. Горбачёвым) можно считать действенным средством в обеспечении взаимопонимания, преодолении конфронтации в мировом масштабе. Гуманитарнокультурологическая проблематика сегодня, бесспорно, оказывает позитивное воздействие на процессы формирования полицентрических систем в их глобальном управлении, задавая вектор их развития.

Указанное направление сотрудничества в ряде государств прежде всего определяет систему взглядов и принципы внешней политической деятельности РФ на современном этапе истории. Культурологические черты и признаки такой системы взглядов, в свою очередь, находят ясное выражение в «Концепции внешней политики РФ», утвержденной Медведевым в июле 2008 года. Симптоматично, что в материалах современных СМИ России нередко проводится мысль о том, что руководство волнуют проблемы поднятия имиджа своей страны в глазах мирового сообщества. Понятно, что эта проблема в самом начале третьего десятилетия XXI века органично вписывается в процесс глобализации.

Так, в интересующей нас сфере (современные СМИ России) «публичной дипломатии» активно популяризируется работа целого ряда агентств, фондов или телерадиостанций: «РИА - Новости»; «Голос России»; «Russia Today»; «Русский мир». Их усилиями прежде всего ведётся пропаганда изучения родного (то есть русского) языка и культуры. Но к результатам их деятельности относят по-разному. К примеру, Яркими показателями симбиоза российской политики и культуры являются, к примеру, политолог Николас Гулл со смешанным чувством насмешки и идейного пафоса назвал этот вид дипломатии «интервенцией в умы, сердце и душу людей, а кроме того и эффективным способом воздействия на культуру суверенных государств» [15, с.77].

А Б. Ширяев, что такого рода дипломатия - это «ключевой фактор в обеспечении национальной безопасности РФ, способ активного сохранения её суверенитета и территориальной целостности, ясный признак консолидации общества, можно сказать, панацея успешного разрешения множества внутренних и внешних проблем на межгосударственном уровне» [13, с.264].

Российская Федерация осуществляет поступательное движение в данном направлении. Так, с 2007 года на её территории функционирует фонд под названием «Русский мир», с 2008 года - «Федеративное агентство по делам СНГ» (Россотрудничество). В соответствии с подписанными в феврале 2010 г. распоряжениями Президента РФ, активно работают и некоторые другие благотворительные Фонды. Таким образом, совершенно очевидно, что международное сотрудничество в России 
наших дней охватывает очень широкую область государственной деятельности. В 2011 году Президентом РФ был подписан документ «Основные направления», явившийся базовым для осуществления дальнейшей работы в указанном направлении.

В настоящее время МИД России также ведёт работу над созданием Концепции в сфере культурного сотрудничества стран - участников СНГ. Актуальность названных документов нельзя переоценить, поскольку они сегодня являются концептуальной базой в деятельности российских ведомств и министерств. Они же содействуют также и дальнейшему росту культурной национальной политики и публичной дипломатии Российского государства в целом.

Политика в области международного права сотрудничества есть, безусловно, неотъемлемая составная часть общей политики РФ. Не секрет, что в современном мировом многополярном порядке всё более усиливается конкуренция, а наряду с ней существенно возрастает также и соперничество в культурном измерении. Здесь, на наш взгляд, уместным будет подчеркнуть широту полномочий Организации. В ведении ЮНЕСКО не только культура, но также экономика и политика, которую не упускают из виду и в правительстве РФ. Специфические формы публичной дипломатии работают на укрепление авторитета РФ на международной сцене. Приходится даже констатировать, что Россия на протяжении очень длительного времени действовала с позиций именно «жёсткой силы». Быть может, это с трудом и, как говорится, придыханием фиксируют в научных трудах либо популярных издательствах некоторые современные русские учёные - политики, политологи и культурологи. В то же время данным обстоятельством вполне охотно делятся такие азербайджанские исследователи, как Али Гасанов, А. Аббасбейли и другие в достаточно известных в нашей республике монографиях.

Хочется заметить, что слово «дипломатия», в которой, казалось, заложен смысл «расчёта на лояльность» или тонкое психологическое умение вникнуть в суть проблем, отнюдь не противоречит позиции «жёсткой силы». Политики-международники и культурологи в таких случаях прежде всего имеют в виду военную, экономическую, а с недавнего времени - ещё и энергетическую мощь. Однако, говоря о так называемой «мягкой силе» (термин ведущих современных русских и европейских культурологов), которая реализуется посредством культурно-гуманитарных инструментов, то следует указать на то, что она зачастую проигрывала.

И в данном случае одна стратегия не противоречит другой, но напротив, органично дополняет её. Об этом, в частности писал современный культуролог и политик Долинский. «Мягкая сила» в противовес так называемой «жёсткой» В РФ в системе современной «публичной дипломатии» чаще всего сочетает в себе традиционный взгляд на культуру и маркетинговые формы» [2]. Причём, большинство современных учёных-теоретиков сходятся во мнении, что симбиоз старого и нового подходов даёт как краткосрочный, так и долгосрочный позитивный эффект при воздействии на иностранную для России аудиторию.

Основной задачей, стоящей в наши дни перед международным культурно-гуманитарным сотрудничеством, становится стимулирование у населения других государств желания ближе ознакомиться с культурой России. Во-первых, это своеобразная «визитная карточка» для экспортёров в разных областях. Во-вторых, ориентация на дальнейшее развитие национальной культуры не в ущерб другим странам.

Характерно в этом ключе следующее замечание М.А. Старчака: «Практика показала, что все происходящее в современном мире - развитие наук, искусства, высоких технологий, необходимо доносить до всех стран Содружества. Однако, их перевод на национальные языки настолько сложен и проблематичен, что оценивается в миллионы долларов. Найти такое количество средств и кадров невозможно. Английский язык как решение тоже не совсем эффективен, т.к. в России и некоторых других странах-членах ЮНЕСКО им, по подсчётам специалистов-статистов, владеют мизерное количество людей - 1-2 процента от численности наций. К тому же не все продвинутые деятели культуры, науки и образования могут читать специальную литературу в своей области на английском языке, а изучать свое направление могут и вовсе единицы. Таким образом, единственной доступной возможностью приобщиться к новейшим мировым научным, информационным и культурным тенденциям становится русский язык» [10].

Отчасти по указанной Старчаком причине остро встаёт для РФ вопрос о более глубоком внедрении национального языка в различные культурные области. Ведь и само развитие национального потенциала России посредством популяризации государственного языка находится не только в прямом ведении ЮНЕСКО, но и распространяется Организацией через уполномоченных лиц на территории ближнего и дальнего зарубежья. Кстати сказать, это правило вполне приложимо и к Азербайджану. В популяризации русского языка в нашей республике ЮНЕСКО также играет немалую роль. Так, в культурной политике посла ЮНЕСКО Мехрибан Алиевой в полном согласии с целями данной Организации многократно подчёркивалось, что с помощью изучения русского языка как иностранного человек из хранителя истины становится доподлинно живым существом. А язык при этом выступает как важнейшее, а, может, и вообще первейшее средство общения и передачи культурно- 
го наследия. Таким образом, очевидно, что язык любой нации есть отражение её многовекового культурного наследия, форма существования и кладезь народной памяти. Это продукт культуры, его составная часть, являющаяся своеобразным хроникёром в деле формирования и трансляции культурных кодов.

Д. Медведев в одном из своих выступлений подчеркивал: «В свете всемерно проводимой культурной политики в России, защищаемой со стороны высоких представителей ЮНЕСКО, совершенно не стоит бояться на эти нужды тратить немалые деньги, потому что в конечном итоге эффект от такого рода работы с людьми любых профессий из других стран, владеющих русским, очень высок. Его себестоимость является надёжным гарантом приоритетности культурной политики России» [1].

Одним из этих гарантов, по мнению многих дальновидных современных политиков и является дальнейшее развитие и совершенствование «публичной дипломатии» в РФ. И на соответствующих форумах в правительстве России активно обсуждаются меры, спо- собствующие этому процессу. Во всяком случае, никто из профессиональных политиков или культурологов сегодня не отрицает того факта, что в международном гуманитарно-культурологическом сотрудничестве могут принимать участие и негосударственные организации. Так, в «Основных положениях» говорится, что в данном процессе «правительство России с одобрения ЮНЕСКО имеет возможность и, собственно говоря, делает это сегодня, вкладывать внебюджетные финансовые средства в пределах государственного или же частного партнерства» [12. Приложение № 1].

Итак, из всего вышеизложенного в настоящей статье нетрудно прийти к выводу, что «публичная дипломатия» является одним из важных и актуальных в наши дни инструментов культурной политики России в целом. Более того её можно считать одной из форм плодотворного сотрудничества между странами-членами ЮНЕСКО и в мировом масштабе. Эта стратегическая линия объединяет в себе несколько видов или форм массовой и элитарной культуры. И это особенно заметно в политике России в современный период.

\section{ЛИТЕРАТУРА}

1. Выступление Д.А. Медведева во время официального визита во Вьетнам. Официальный сайт Президента Российской Федерации. [Электронный ресурс]. Режим доступа: http//www.kremlin.ra/transcripts/9386. (дата обращения 17.04.2020).

2. Долинский А.В. Практические вопросы оптимизации российской публичной дипломатии. [Электронный ресурс]. Режим доступа: http//www.russkiymir. ru/. (дата обращения 07.12.2020).

3. Иванова Н. Гибель богов. М.: АСТ ФОЛИО, 1993. 357 с.

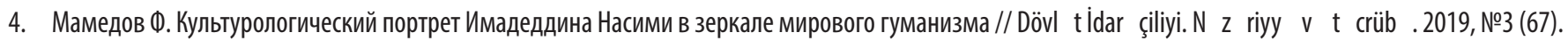
C. 61-75.

5. Материалы Международного общественного форума. «Диалог цивилизаций». 2002-2006. М.: Центра национальной славы России, 2006.

6. Медведев Д.А. Российская дипломатия. М.: Политика, 2017. 401 с.

7. Наджафов Э. Гейдар Алиев о необходимости сохранения и развития ценностей национальной культуры азербайджанского народа в условиях глобализации // Учёные записки БСУ, 2008. Серия общественно-политических наук. С. 101-109.

8. Обзоры мировых СМИ. [Электронный ресурс]. Режим доступа: http://inosmi.ru/overwiew/. (дата обращения 25.07.2020).

9. Померанцев Г.С. Диалог и молчание // Человек, 1996, № 3. С. 61-62.

10. Старчак М. А. Российское образование на русском языке как фактор влияния России в Центральной Азии; что происходит и что делать? [Электронный ресурс]. Режим доступа: http://www.russkiymir.ru/rasskiymir/ra/analytics/article/news0003.html. (дата обращения 11.10.2020).

11. Тимина С.И. Современный литературный процесс (1990-е гг. - начало XXI В.). В кн.: Современная русская литература (1990-е гг. - начало XXI В.). М.-С.Петербург: ACADEMIA, 2005. 350 c.

12. Устав ЮНЕСКО. Брюссель: ЮНЕСКО, 2002.

13. Ширяев Б.А. Внешняя политика США. Санкт-Петербург: СПб, 2007. 344 с.

14. Appadurai A. The New Territories of Culture: Globalization, Cultural Uncertainly and Violence. Keys to The 21 -st Century- UNESCO Publishing. 2001. 199 p.

15. Nicholas J. Cull University of Southern California, Los Angeles, 2007. 211 p.

(с) Кулиева Ламия Аскер гызы (lama2022@inbox.ru) 